\title{
Band Gap Engineering in Zinc Doped Sodium Hexa-titanate
}

\author{
Navshad Alam ${ }^{1}$, Tahira Khatoon ${ }^{1}$, Vishal Singh Chandel ${ }^{2 *}$ and Ameer Azam ${ }^{3}$ \\ 'Department of Physics, Integral University, Lucknow - 226026, Uttar Pradesh, India; navshadkhan@gmail.com, \\ tahira.khatoon.20@gmail.com \\ 2Department of APSH, Rajkiya Engineering College, Ambedkar Nagar - 224122, Akbarpur, Uttar Pradesh, India; \\ chandel.integral@gmail.com \\ ${ }^{3}$ Department of Applied Physics, Zakir Husain College of Engineering and Technology (ZHCET), Aligarh Muslim \\ University (AMU), Aligarh - 202002, Uttar Pradesh, India; azam2288@gmail.com
}

\begin{abstract}
Objectives: In this article Zinc doped Sodium Hexa-titanate ceramic materials were prepared for investigating of optical behaviors. Methods and Analysis: Pure and Zinc doped Sodium Hexa-titanate $\left(\mathrm{Na}_{2} \mathrm{Ti}_{6} \mathrm{O}_{13}\right)$ ceramic materials have been synthesized using solid state route method, by adding sodium carbonate and titanium dioxide in a proper ratio and passes through different process. Structure and phase of all synthesized ceramic materials were analyzed using X-ray diffraction, and found single phase and monoclinic structure of pure and zinc doped samples. Morphology of all synthesized materials has been studied using scanning electron microscopy. Absorption spectra of these Hexa-titanate samples have also been recorded. Findings: The Crystalline size of synthesized samples was calculated with Debye-Scherrer equation, as well as the energy band gaps have been calculated using Tauc relation with respect to absorption wavelength. Application: The energy band gap has been reduced by doping $\mathrm{ZnO}$ from $3.780 \mathrm{eV}$ to $2.779 \mathrm{eV}$. These narrower band gaps can be used in different infrared and thermoelectric sensors.
\end{abstract}

Keywords: Energy Band Gap, Monoclinic, Scanning Electron Microscopy, Sodium Hexa-titanate, Tauc Relation

\section{Introduction}

The common chemical formula of Sodium alkali titanates is $\mathrm{A}_{2} \mathrm{Ti}_{\mathrm{n}} \mathrm{O}_{2 \mathrm{n}+1}$ (where $1 \leq \mathrm{n} \leq 8$ \& $\mathrm{A}=\mathrm{Na}, \mathrm{K}, \mathrm{Li}$, etc.). Along with the different titanates, Sodium Hexa-titanate $\left(\mathrm{Na}_{2} \mathrm{Ti}_{6} \mathrm{O}_{13}\right)$ and Sodium Octa-titanates $\left(\mathrm{Na}_{2} \mathrm{Ti}_{8} \mathrm{O}_{17}\right)$ have excellent applications for instance ion exchange $e^{1,2}$, photocatalysis ${ }^{3}$, sensors ${ }^{4}$. Sodium Hexa-titanate (NHT) has a tunnel structure and these Hexa-titanates materials shows good quality of chemical stability in comparison of open ones. These tunnel crystal or layered structures have a variety of technological applications ${ }^{5}$.

The physical properties of alkali titanates such as ionic, electronic conductivities, and optical, have been investigated on the basis of their potential applications as ion exchangers in industry, filters, electrodes for the purpose of secondary batteries, heat insulators, reinforcements, catalysts.

Sodium Hexa-titante ceramic materials also known as electro-ceramic can be formulated for specific electrical, optical, and magnetic properties. These electrical, magnetic, and optical properties can be tailored by doping transition metals to work it as insulators, highly conductive materials, actuators, sensors, electrodes as well as ferroelectric materials ${ }^{6-9}$ (Figure 1 ).

Pure and zinc doped Sodium Hexa-titanatehave been synthesized using solid state route method. These NHT ceramic materials also have fine applications in biomedical engineering?

Sodium Hexa-titanate ceramic materials can be prepared using various techniques. Such as, sol-gel, solid state route, and hydrothermal method $10-12$. Properties

${ }^{*}$ Author for correspondence 


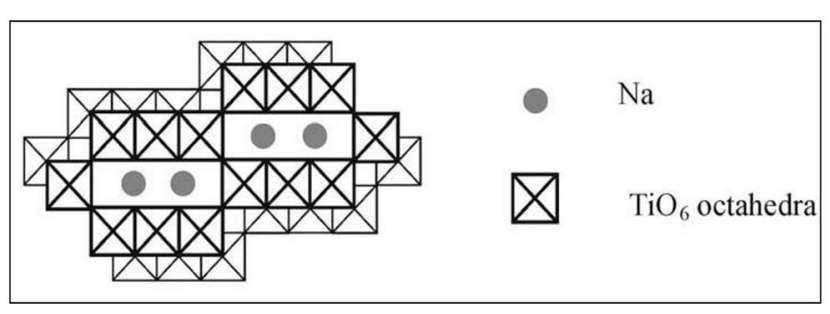

Figure 1. Layered structure of Sodium Hexa-titanate.

of the NHT materials can be tailored by doping various transition metals, such as, Copper $(\mathrm{Cu})$, Zinc $(\mathrm{Zn})$, Nickel $(\mathrm{Ni})$, Iron $(\mathrm{Fe})$, etc.

\section{Synthesis}

NHT ceramic powders can be prepared by adding sodium carbonate $\left(\mathrm{Na}_{2} \mathrm{CO}_{3}\right)$ and titanium dioxide $\left(\mathrm{TiO}_{2}\right)$ in a proper molar ratio.

$$
\mathrm{Na}_{2} \mathrm{CO}_{3}+\mathrm{TiO}_{2} \rightarrow \mathrm{Na}_{2} \mathrm{Ti}_{6} \mathrm{O}_{13}+\mathrm{CO}_{2} \uparrow
$$

In this work, different samples of pure and zinc doped NHT $\left(\mathrm{Na}_{2} \mathrm{Ti}_{6} \mathrm{O}_{13}\right)$ of various molar concentration $(\mathrm{x}=0 \%, 4 \%, 8 \%$ and $12 \%)$ are prepared by solid state route method. The chemical formula of pure and zinc doped NHT are written below:

$$
\begin{aligned}
& \mathrm{Na}_{2} \mathrm{CO}_{3}+5.96 \mathrm{TiO}_{2}+0.04 \mathrm{ZnO} \rightarrow \mathrm{Na}_{2} \mathrm{Ti}_{5.94} \mathrm{Zn}_{0.04} \mathrm{O}_{13} \\
& \mathrm{Na}_{2} \mathrm{CO}_{3}+5.92 \mathrm{TiO}_{2}+0.08 \mathrm{ZnO} \rightarrow \mathrm{Na}_{2} \mathrm{Ti}_{5.92} \mathrm{Zn}_{0.08} \mathrm{O}_{13} \\
& \mathrm{Na}_{2} \mathrm{CO}_{3}+5.88 \mathrm{TiO}_{2}+0.12 \mathrm{ZnO} \rightarrow \mathrm{Na}_{2} \mathrm{Ti}_{5.94} \mathrm{Zn}_{0.04} \mathrm{O}_{13}
\end{aligned}
$$

$\mathrm{Na}_{2} \mathrm{Ti}_{6} \mathrm{O}_{13}$ ceramics have been prepared by solid-state route method, taking proper amount of sodium carbonate $\left(\mathrm{Na}_{2} \mathrm{CO}_{3}\right)$ AR grade and titanium dioxide $\left(\mathrm{TiO}_{2}\right)$ Sigma Andrich, having $99.5 \%$ purity powders.

After adding sodium carbonate and titanium dioxide, powders were grinded accurately for many hours using pistel mortar to make it smaller in size. After that these grinded materials were kept in a programmable muffle furnace. First set it to reach at $900^{\circ} \mathrm{C}$ with controlled heating rate of 4 degree Celsius per minute then kept back it constant for 12 hours, and after that it reaches at room temperature. To prepare pure and zinc doped ( $\mathrm{x}=0 \%, 4 \%, 8 \%$ and $12 \%$ molar) specimens, required amount of zinc oxide $(\mathrm{ZnO})$ powder were added in a mixture of $\mathrm{TiO}_{2}$ and $\mathrm{Na}_{2} \mathrm{CO}_{3}$ and obtained ceramic materials were gone through the same process as described above for pure sample.

\section{Results}

\subsection{XRD Analysis}

The X-Ray Diffraction (XRD) patterns of pure and zinc doped NHT are recorded at room temperature and found monoclinic structure and single phase formation as shown in Figure 2. It has been also confirmed that after adding $\mathrm{Zn}$ in pure Sodium Hexa-titante no impure peaks were observed, which clearly indicates that zinc has replaced titanium accurately and doping was successful.

By calculating crystalline size, it has found that on increasing the zinc and reducing the titanium in pure NHT, unit volume of prepared samples gradually decreases. The most appropriate possible reason is that, particle size of the doped Sodium Hexa-titanate has been decreases on increasing the zinc in pure NHT which have also been confirmed by morphological study (Table 1).

Table 1. Crstalline size of pure and $\mathrm{Zn}$ doped Sodium Hexa-titanate

\begin{tabular}{|c|c|c|}
\hline Sl. No. & Samples Name & Mean Crstalline Size ( $\boldsymbol{\tau})$ \\
\hline 1. & $\mathrm{Na}_{2} \mathrm{Ti}_{6} \mathrm{O}_{13}$ & 0.210 \\
\hline 2. & $\mathrm{Na}_{2} \mathrm{Ti}_{5.96} \mathrm{Zn}_{0.04} \mathrm{O}_{13}$ & 0.202 \\
\hline 3. & $\mathrm{Na}_{2} \mathrm{Ti}_{5.92} \mathrm{Zn}_{0.08} \mathrm{O}_{13}$ & 0.20 \\
\hline 4. & $\mathrm{Na}_{2} \mathrm{Ti}_{5.88} \mathrm{Zn}_{0.12} \mathrm{O}_{13}$ & 0.20 \\
\hline
\end{tabular}

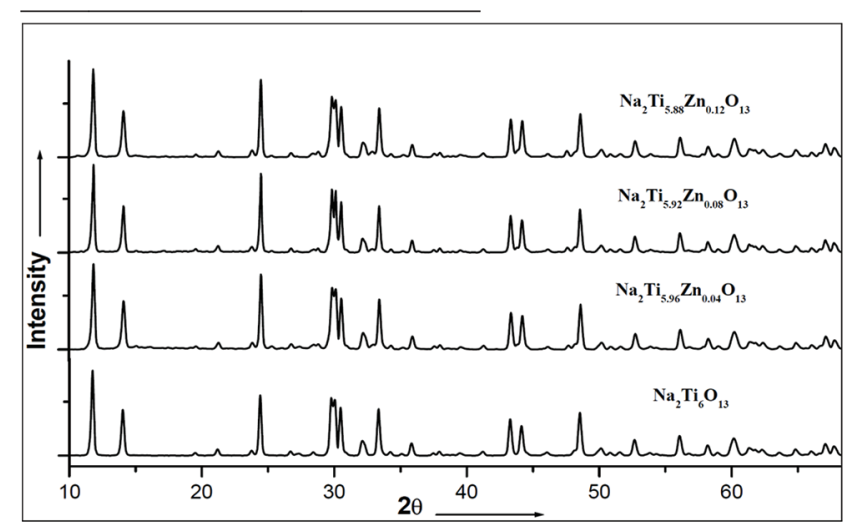

Figure 2. XRD analysis of pure and zinc doped Sodium

Hexa-titanmate.

Crystalline size of pure and doped NHT are calculated by Debye-Scherrer equation. 


$$
\alpha=\frac{K \lambda}{\beta \cos \theta}
$$

Where $\tau$ denotes mean size of the crystalline, and $K$ is a dimension less shape factor having a constant value of $0.91, \lambda$ is the $X$-ray wavelength, and $\lambda=1.5406 \AA$ ( $\mathrm{Cu} \mathrm{K}$-alpha), $\beta$ denotes full width half maxima and obtained from X-ray diffraction, and $\theta$ is Bragg angle which is also obtained from X-ray diffraction.

\subsection{FE-SEM Analysis}

Structure and shape of all synthesized materials were studied using Field Emission Scanning Electron Microscopy. Morphology of pure and zinc doped Sodium Hexa-titanatewere observed using FE-SEM (Nova NanoSEM 450) at an accelerating voltage of $10 \mathrm{kV}$. Figure 3a, 3b, 3c, and 3d) clearly shows the microstructure of all synthesized pure and zinc doped NHT materials and found that these materials have rod shape. Pure Sodium Hexa-titanatehave a diameter between 0.1 micrometer to 0.25 micrometer and where length of the rod lies in the range of 0.8 to 1.3 micrometer as shown in Figure 3a. The other zinc doped Sodium Hexa-titanateceramic having diameter in the range of 0.1 to $0.25 \mu \mathrm{m}$, and length of the rod lies between 0.7 to $1.2 \mu \mathrm{m}$ shown in Figure $3 \mathrm{~b}, 3 \mathrm{c}$, and $3 \mathrm{~d}$.

Table 2 shows average size of rod shape pure and zinc doped Sodium Hexa-titante alkali titante ceramic materials.

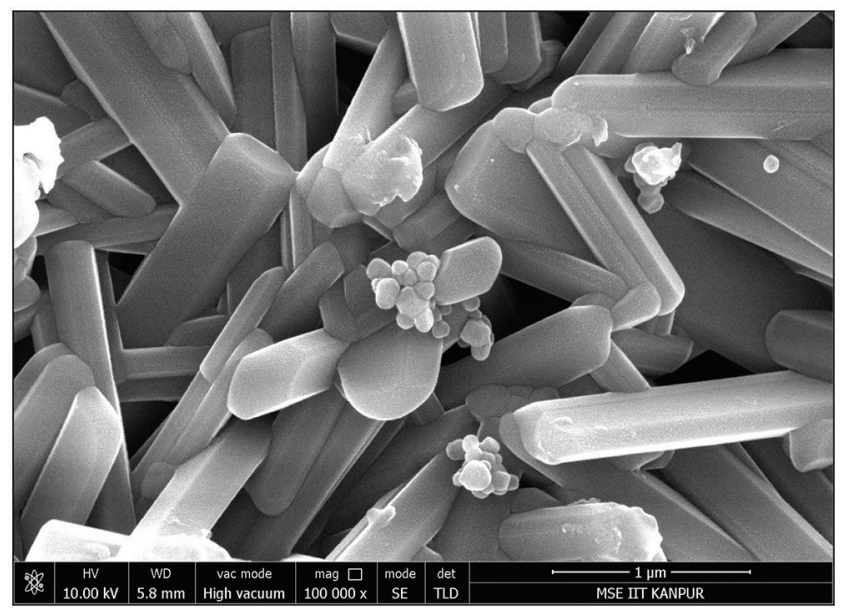

Figure 3a. SEM image of pure Sodium Hexa-titanates.

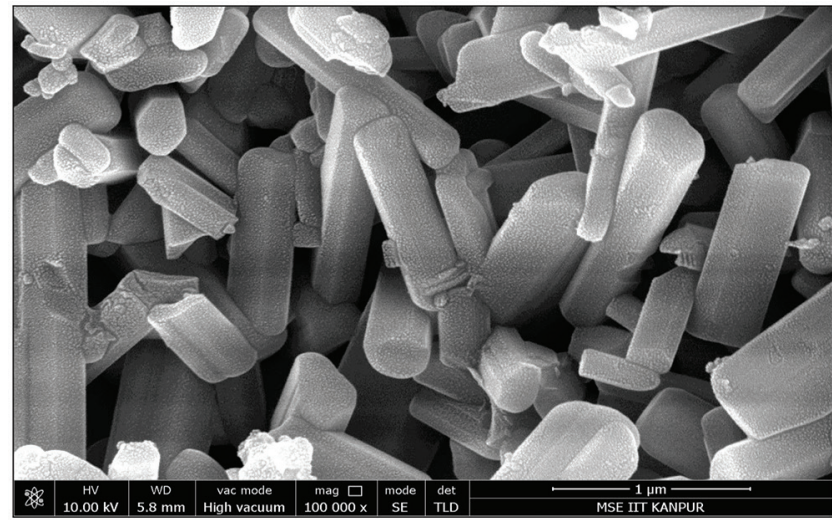

Figure $3 \mathbf{b}$. SEM image of $4 \% \mathrm{Zn}$ doped Sodium Hexa-titanate.

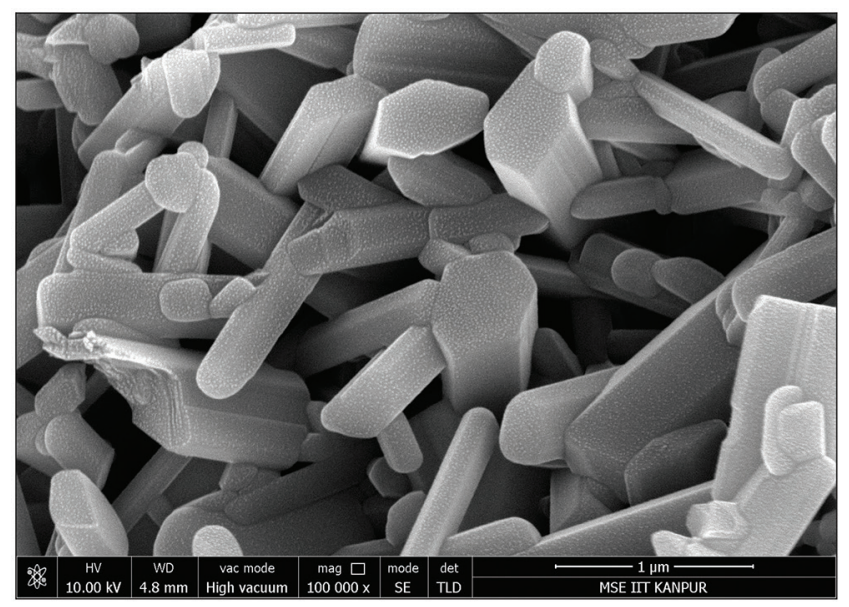

Figure 3c. SEM image of $8 \% \mathrm{Zn}$ doped Sodium Hexatitanate.

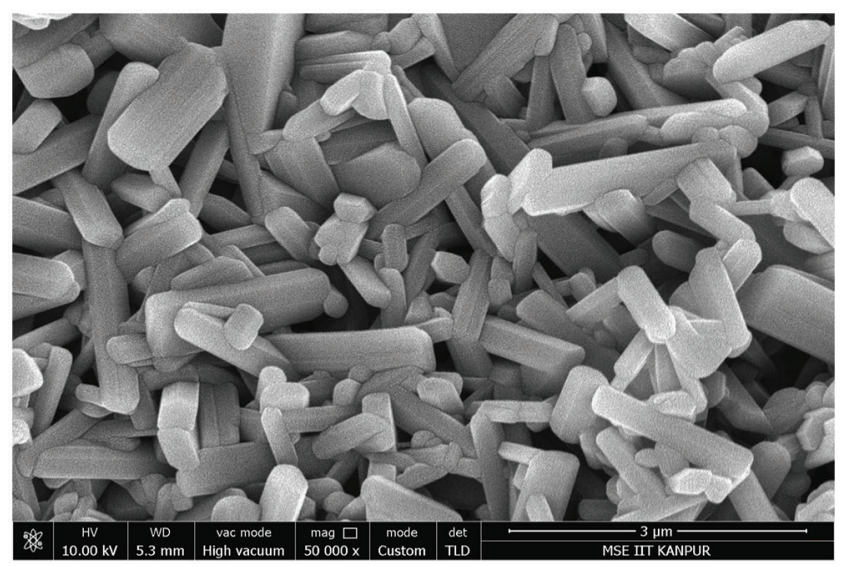

Figure 3d. SEM image of $12 \% \mathrm{Zn}$ doped Sodium Hexa-titanate. 
Table 2. Particle size of pure and zinc doped Sodium Hexa-titanate.

\begin{tabular}{|c|c|c|}
\hline Sl. No. & Samples Name & Average Length of Rod \\
\hline 1. & $\mathrm{Na}_{2} \mathrm{Ti}_{6} \mathrm{O}_{13}$ & $1.2 \mu \mathrm{m}$ \\
\hline 2. & $\mathrm{Na}_{2} \mathrm{Ti}_{5.96} \mathrm{Zn}_{0.04} \mathrm{O}_{13}$ & $1.10 \mu \mathrm{m}$ \\
\hline 3. & $\mathrm{Na}_{2} \mathrm{Ti}_{5.92} \mathrm{Zn}_{0.08} \mathrm{O}_{13}$ & $1.076 \mu \mathrm{m}$ \\
\hline 4. & $\mathrm{Na}_{2} \mathrm{Ti}_{5.88} \mathrm{Zn}_{0.12} \mathrm{O}_{13}$ & $1.06 \mu \mathrm{m}$ \\
\hline
\end{tabular}

\subsection{UV-Vis Spectroscopy}

The absorption wavelength of pure and zinc doped Sodium Hexa-titanate recorded at room temperature by UV-Vis spectrophotometer. The absorption wavelength gradually increases as dopant percent of zinc increases in pure Sodium Hexa-titanate. The absorption peaks of pure and zinc doped Sodium Hexa-titanate have been observed at $328 \mathrm{~nm}, 358 \mathrm{~nm}, 373 \mathrm{~nm}$, and $447 \mathrm{~nm}$ for pure, $4 \%, 8 \%$ and $12 \%$ respectively.

Using Tauc relation, energy band gap of pure doped Sodium Hexa-titanatehave been calculated the value of absorbance with respect to wavelength the energy band gap has been calculated by,

$$
\alpha h v=A\left(h v-E_{g}\right)^{n}
$$

Where, $\alpha=$ absorption coefficient, $h v=$ energy of light, $\mathrm{E}_{\mathrm{g}}=$ energy band gap, $\mathrm{n}=$ nature of transition (here nature of transition is direct allowed transition, therefore $n=1 / 2$ ), $\mathrm{A}=$ constant.

Researchers have reported that energy band gap of pure Sodium Hexa-titnate lies between $2.78 \mathrm{eV}$ to $3.78 \mathrm{eV} \underline{13}$.

Figure 4 reveals the energy band gap for pure and zinc doped materials. It has found that energy band gap decreases with increasing concentration of zinc in pure Sodium Hexa-titanate which is shown in Table 3 on the basis of the colors. The narrow energy band gap have several advantages and applications. Materials having narrow band gap can be used in nanoscale spin filters, as infrafred sensors ${ }^{14}$. At larger dimension quantum confinement effect can be observed in a narrower band gap materials for tiny effectivly masses $\underline{15}, \underline{16}$.

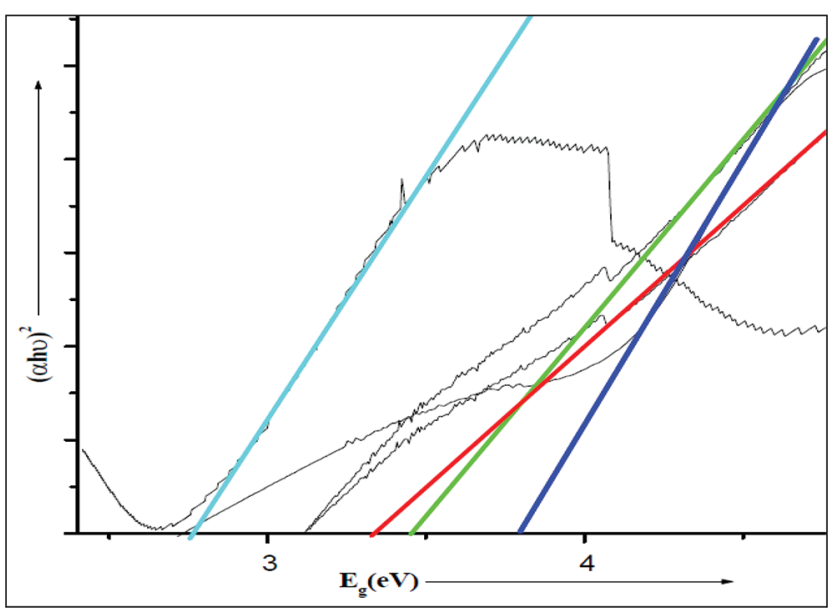

Figure 4. Band gap analysis of zinc doped Sodium Hexa-titnate.

\section{Summary and Conclusions}

Sodium Hexa-titanate were prepared using solid-state reaction method and calcined at high temperature with controlled heating rate for several hours. X-ray diffraction analysis gives the information of phase and structure of the synthesized materials. Morphologies of pure and doped Hexa-titanate were studied by scanning electron microscopy. The properties of Sodium Hexa-titanate were tailored by doping $\mathrm{ZnO}$ which replaced $\mathrm{TiO}_{2}$. Furthermore it has found that crystalline size as well as particle size of $\mathrm{Zn}$ doped Sodium Hexatitanate ceramic materials slightly decreases on increasing the concentration of zinc in Sodium Hexa-titanate. Absorption wavelength was obtained using UV-Vis spectroscopy, using these absorption wavelengths energy band gap has also been calculated with the help of Tauc

Table 3: Absorption wavelegth and energy band gap of doped Sodium Hexa-titanate.

\begin{tabular}{|c|c|c|c|c|}
\hline Sl. No. & Colors & Samples Name & Absorption & Energy Band Gap \\
\hline 1. & Blue & $\mathrm{Na}_{2} \mathrm{Ti}_{6} \mathrm{O}_{13}$ & $328 \mathrm{~nm}$ & $3.780 \mathrm{eV}$ \\
\hline 2. & Green & $\mathrm{Na}_{2} \mathrm{Ti}_{5.96} \mathrm{Zn}_{0.04} \mathrm{O}_{13}$ & $358 \mathrm{~nm}$ & $3.471 \mathrm{eV}$ \\
\hline 3. & Red & $\mathrm{Na}_{2} \mathrm{Ti}_{5.92} \mathrm{Zn}_{0.08} \mathrm{O}_{13}$ & $373 \mathrm{~nm}$ & $3.325 \mathrm{eV}$ \\
\hline 4. & Cyan & $\mathrm{Na}_{2} \mathrm{Ti}_{5.88} \mathrm{Zn}_{0.12} \mathrm{O}_{13}$ & $447 \mathrm{~nm}$ & $2.779 \mathrm{eV}$ \\
\hline
\end{tabular}


relation. Since energy band gap is inversely proportional to absorption wavelength, therefore energy band gap decreases with increasing absorption wavelength.

\section{Acknowledgment}

Authors are thankful to the Research and Development of Integral University, Lucknow for providing the research facilities and manuscript communication number IU/R\&D/2019-MCN000607. Authors are also thankful to Dr. Sri Siva Kumar, Associate Professor, Department of Chemical Engineering and Material Science Programme, IITK, for providing the experimental facility. One of the authors is thankful to MHRD TEQIP-III scheme at REC Ambedkar Nagar, for providing financial assistance to this project.

\section{References}

1. Izawa H, Kikkawa S, Koizumi M. Ion exchange and dehydration of layered [sodium and potassium] titanates, $\mathrm{Na}_{2} \mathrm{Ti}_{3} \mathrm{O}_{7}$ and $\mathrm{K}_{2} \mathrm{Ti}_{4} \mathrm{O}_{9}$, J. Phys. Chem. 1982; 86:5023-26. https://doi.org/10.1021/j100222a036.

2. Papp S, Kõrösi L, Meynen V, Cool P, Vansant EF, Dékány I. The influence of temperature on the structural behaviour of sodium tri- and hexa-titanates and their protonated forms, J. Solid State Chem. May 2005; 178:1614-19. https://doi. org/10.1016/j.jssc.2005.03.001.

3. Suetake J, Nosaka AY, Hodouchi K, Matsubara H, Nosaka Y. Characteristics of Titanate Nanotube and the States of the Confined Sodium Ions, The Journal of Physical Chemistry C. 2008 ; 112(47):18474-82. DOI: 10.1021/jp8069223. https://doi.org/10.1021/jp8069223.

4. Tsai JY, Chao JH, Lin CH, Low temperature carbon monoxide oxidation over gold nanoparticles supported on sodium titanate nanotubes, Journal of Molecular Catalysis A: Chemical. 2009; 298:115-24. https://doi.org/10.1016/j. molcata.2008.10.019.

5. Wang L, Chen Q, Wang R. H. Synthesis and characterization of $\mathrm{K}_{2} \mathrm{Ti}_{6} \mathrm{O}_{13}$ nanowires, Chem. Phys. Lett. 2003; 376:726-31. https://doi.org/10.1016/S0009-2614(03)01068-6.

6. Tournoux M, Marchand R, Brohan L. Layered $\mathrm{K}_{2} \mathrm{Ti}_{4} \mathrm{O}_{9}$ and the open metastable $\mathrm{TiO} 2(\mathrm{~B})$ structure, Prog. Solid
St. Chem. 1986; 17:33-52. https://doi.org/10.1016/00796786(86)90003-8.

7. Janes R, Knightley LJ. Crystallization and phase evolution of potassium titanates from alkoxide derived precipitates, Journal of Materials Science. 2004; 39:2589-92. https://doi. org/10.1023/B:JMSC.0000020035.67862.65.

8. Ramirez J, Fabry P. Investigation of a reference electrode based on perovskite oxide for second kind potentiometric gas sensor in open systems, Sensors and Actuators B. 2001; 77:339-45. https://doi.org/10.1016/S0925-4005(01) 00724-9.

9. Li GH, Hong JM. Synthesis of K2Ti6O13 whiskers by the method of calcination of $\mathrm{Kf}$ and $\mathrm{TiO} 2$ mixtures, Mat. Res. Bull. 1999; 34:2341-49. https://doi.org/10.1016/S00255408(99)00229-9.

10. Siddiqui MA, Chandel VS, Sharique M, Azam A. Comparative study of potassium hexatitanate $\left(\mathrm{K}_{2} \mathrm{Ti}_{6} \mathrm{O}_{13}\right)$ whiskers prepared by sol-gel and solid state reaction routes, Applied Surface Science. 2012; 258:7354-58. https://doi. org/10.1016/j.apsusc.2012.04.018.

11. Vikram SV, Phase DM, Chandel VS. Synthesis, characterization, and electrical studies on Cu-doped K2Ti6O13 lead-free ceramics: Role of defect associate dipoles, Journal of Alloys and Compounds. 2010; 489:70007. https://doi.org/10.1016/j.jallcom.2009.09.157.

12. Siddiqui MA, Chandel VS, Sharique M, Azam A. Dielectric and spectroscopic analysis of cobalt doped potassium hexatitanate (K2Ti6O13) ceramics, Materials Science-Poland. 2013; 31:555-60. https://doi.org/10.2478/ s13536-013-0139-z.

13. Khan SA, Khan IA, Khan MS, Zaherab M, Arshad M. Na2Ti6O13 belts: A comparative study on structural, optical and morphological properties prepared by sol-gel and solid state reaction routes, Archives of Applied Science Research. 2015; 7(1):42-47.

14. Gilberta MJ, Birda JP, Sugayab T, Akis R. Application of narrow band-gap materials in nanoscale spin filters, Physica. B. 2002; 314:230-34. https://doi.org/10.1016/S0921-4526(01)01446-6.

15. McGill TC, Collins DA. Prospects for the future of narrow band gap materials, Semiconductor Science and Technology. 1993; 8. https://doi.org/10.1088/0268-1242/8/1S/001.

16. Kasap S, Capper P. Springer Handbook of Electronic and Photonic Materials, Springer International Publishing. 2017; 2. https://doi.org/10.1007/978-3-319-48933-9. 